\title{
Urinary crystalloid excretion in patients with inflammatory bowel disease
}

RICHARD I. BREUER ${ }^{1}$, EUGENE A. GELZAYD ${ }^{2}$, AND

JOSEPH K. KIRSNER

From the Gastrointestinal Section, Department of Medicine, University of Chicago, Chicago, Illinois, USA

SUMMARY Because of the potential relationship of increased urinary crystalloid excretion and concentration to stone formation, urinary calcium and uric acid excretion patterns were studied prospectively in 65 patients with inflammatory bowel disease and compared with excretion patterns in patients with functional bowel disease (controls) receiving similar dietary prescriptions.

Mean 24-hr urinary calcium excretion was higher in both ulcerative colitis $(212 \mathrm{mg}, \mathbf{P}<0.02)$ and granulomatous bowel disease $(168 \mathrm{mg}, \mathrm{P}=\mathrm{n} . \mathrm{s}$.) than in controls $(118 \mathrm{mg})$. Urinary calcium excretion exceeded $250 \mathrm{mg} / 24 \mathrm{hr}$ in 11 of 34 patients with inflammatory bowel disease but in none of the controls. Eight of these 34 patients compared with one of 10 controls excreted urine with calcium concentrations greater than $20 \mathrm{mg} / 100 \mathrm{ml}$.

Mean 24-hr uric acid excretion was slightly higher in granulomatous bowel disease $(520 \mathrm{mg})$ than in ulcerative colitis $(450 \mathrm{mg})$ or functional bowel disease $(451 \mathrm{mg})$. Eight patients with inflammatory bowel disease but no control subject excreted $>700 \mathrm{mg}$. The mean urinary uric acid concentration was significantly higher in ulcerative colitis $(538 \mu \mathrm{g} / \mathrm{ml}, \mathrm{P}<0.05)$ and granulomatous bowel disease $(558 \mu \mathrm{g} / \mathrm{ml}, \mathrm{P}<0.02)$ than in controls $(338 \mu \mathrm{g} / \mathrm{ml})$. The mean morning urine $p \mathrm{H}$ was lower $(5 \cdot 5, \mathrm{P}<0.01)$ in ulcerative colitis than in the other groups.

These results indicate increased excretion and higher concentration of calcium and uric acid in some patients with inflammatory bowel disease on the usual treatment programmes. Only very long-term prospective studies of such patients can help to document the true contribution of increased crystalloid concentration and excretion to kidney stone formation in inflammatory bowel disease patients.

Patients admitted to hospital with chronic inflammatory bowel diseases seem predisposed to kidney stones composed of calcium salts or uric acid. The incidence of urolithiasis among hospital patients in general is approximately $1: 1,000$ $(0 \cdot 1 \%)$, whereas the incidence of stone formation among inpatients with inflammatory bowel disease may be $6 \%$ or higher (Deren, Porush, Levitt, and Khilnani, 1962; Gelzayd, Breuer, and Kirsner, 1968, Table I). In a recent retrospective study (Gelzoyd et al, 1968) 14 of 79 patients $(18 \%)$ with ileostomies and 21 of 208 patients $(10 \cdot 1 \%)$ with granulomatous bowel disease had evidence of kidney stones (Table I), suggesting that certain groups may be particularly at risk. The medical and economic importance of calculus disease in these patients was emphasized by the necessity for further hospital admission of more than one half of the inflammatory bowel disease patients who formed kidney stones exclusively for management of this complication (Gelzayd et al, 1968).

Consideration of the possible connexion be${ }^{1}$ Present address: Department of Medicine, Evanston Hospital Evanston, Illinois 60201 .

2Present address: 300 Northland Medical Building, Southfield, Michigan 48075 . 


\begin{tabular}{lcc}
\hline Reference & No. of Subjects & No. of Stones \\
\hline $\begin{array}{l}\text { Deren et al (1962) } \\
\text { Mařataka } \text { et al (1964) }\end{array}$ & 583 & $28(4.8 \%)$ \\
$\begin{array}{l}\text { Ileostomy } \\
\text { Gelzayd } \text { et al (1968) }\end{array}$ & 512 & $10(1.0 \%)$ \\
$\quad$ Ulcerative colitis & 885 & $9(13.0 \%)$ \\
$\begin{array}{l}\text { Granulomatous } \\
\text { bowel disease }\end{array}$ & 667 & $64(7.2 \%)$ \\
Totals & 208 & $43(6.4 \%)$ \\
\hline
\end{tabular}

Table I Incidence of urolithiasis in patients with inflammatory bowel disease

tween inflammatory bowel disease and the subsequent development of urolithiasis has led us to examine crystalloid concentration and excretion and physiochemical properties of the urine in patients with inflammatory bowel disease. This report presents a preliminary prospective study over one year in which these parameters in inflammatory bowel disease patients and appropriate control subjects in hospital are compared. Significant differences were observed between these groups despite the fact that the inflammatory bowel disease patients in this series had not yet developed kidney stones.

\section{Methods for Selection of Patients for Study}

The study group consisted of 120 consecutive patients with ulcerative colitis, ileocolitis, and regional enteritis (granulomatous bowel disease), admitted to the gastroenterology service of the University of Chicago Hospitals between September 1965 and September 1966. Twenty patients with functional bowel disease admitted during this period served as the control group.

The average age of the ulcerative colitis patients was 33 years, of the granulomatous bowel disease patients 29 years, and of the functional bowel disease group 48 years.

At the time of the study, no subject was receiving intravenous fluids and all were well enough to consume a standard non-laxative, low-residue diet calculated to contain between 400 and $800 \mathrm{mg}$ of calcium and 100 and $300 \mathrm{mg}$ of purines per day. Water intake was not controlled; however, no patient was clinically dehydrated and the adequacy of urine collections was assured (see below). Twenty-five of 35 patients with ulcerative colitis and 24 of 29 with the granulomatous bowel diseases received corticosteroids during the period of study; no patient in the control group received steroids.

The study plan was designed to coincide with the general medical care of the patient; we obtained relatively complete data from 65 patients with inflammatory bowel disease. Serum concentrations of calcium, phosphorus, enzymatic uric acid (Sorensen, 1960), sodium, potassium, chloride, carbon dioxide, and creatinine were measured. At least two 'clean-catch' morning urine specimens (collected fasting, before the morning (alkaline tide') were tested for $p \mathrm{H}$, using limited range $p \mathrm{H}$ paper $(p \mathrm{H} 4 \cdot 5-7 \cdot 0)$. Twenty-four hour urine specimens were collected for determination of volume, uric acid by the enzymatic method (Sorensen, 1950), calcium, sodium, potassium, and chloride. Plain films of the abdomen and intravenous urograms were made. No patient studied had either significant renal insufficiency (BUN $<25 \mathrm{mg} \%$ and serum creatinine $<1.4 \mathrm{mg} \%$ ) or active urinary tract infection (quantitative bacterial colony count < $100,000 / \mathrm{ml}$ ). Urine collections containing less than $1,300 \mathrm{mg}$ creatinine in men and $1,000 \mathrm{mg}$ in women were considered incomplete and either discarded or repeated.

\section{Results}

Calcium excretion among the control and inflammatory bowel disease subjects is presented in Table II. Mean urinary calcium excretion was higher in both ulcerative colitis ( $212 \mathrm{mg}$ per $24 \mathrm{hr}$ ) and granulomatous bowel disease patients (167 per $24 \mathrm{hr}$ ) than in the controls $(118 \mathrm{mg}$ per $24 \mathrm{hr}$ ). For the ulcerative colitis group, this difference was statistically significant $(P<0.02)$. Urinary calcium excretion exceeded $250 \mathrm{mg}$ per 24 hours in 11 of 34 inflammatory bowel disease patients; none of the controls exhibited this magnitude of calciuria. Although mean urinary calcium concentration was similar in the three groups, eight of 34 inflammatory bowel patients compared with only one of 10 control subjects

\begin{tabular}{|c|c|c|c|}
\hline Disease & No. of Patients & $\begin{array}{l}\text { Calcium Excretion } \\
(\bar{x} \pm S E M, m g / 24 h r)\end{array}$ & $\begin{array}{l}\text { Calcium Concentration } \\
(\bar{x} \pm S E M, \mathrm{mg} / 100 \mathrm{ml})\end{array}$ \\
\hline $\begin{array}{l}\text { Ulcerative colitis } \\
\text { 'Granulomatous' bowel disease } \\
\text { Functional bowel disease (control) }\end{array}$ & $\begin{array}{l}20 \\
14 \\
10\end{array}$ & $\begin{array}{l}212 \pm 32(8)^{1,3} \\
168 \pm 34(3)^{4} \\
119 \pm 45(0)\end{array}$ & $\begin{array}{ll}13 \cdot 7 \pm 1 \cdot 8 & {[5]^{2}} \\
14 \cdot 2 \pm 2 \cdot 7 & {[5]} \\
12 \cdot 8 \pm 1 \cdot 9 & {[1]}\end{array}$ \\
\hline
\end{tabular}

Table II Urinary calcium excretion and concentration

${ }^{1}$ () $=$ no. patients $>250 \mathrm{mg}$

${ }^{2}[]=$ no. patients $>20 \mathrm{mg} / 100 \mathrm{ml}$

${ }^{3} P<0.02$

? , n.s. 
excreted urine with calcium concentration in excess of $20 \mathrm{mg}$ per $100 \mathrm{ml}$.

Mean 24-hr urine volumes were $1,525 \mathrm{ml}$ for ulcerative colitis patients, $1,480 \mathrm{ml}$ for regional enteritis patients, and $1,046 \mathrm{ml}$ for functional bowel disease patients during the calcium study $(P<0.05$, for ulcerative colitis vs functional bowel disease). No patient was clinically dehydrated and there was no direct correlation between calcium excretion or concentration and urine output in the ulcerative colitis group $(r=0 \cdot 178)$.

Mean urinary sodium excretion $(\bar{x} \pm \mathrm{SEM}$, $\mathrm{mg} / 24 \mathrm{hr}$ ) was $102 \cdot 5 \pm 13$ for ulcerative colitis subjects, $130 \pm 15$ in regional enteritis subjects, and $70 \pm 11$ in control subjects $(P<0.01$ for regional enteritis vs functional bowel disease). Both sodium concentration and excretion varied directly with calcium concentration in all three groups. For ulcerative colitis subjects $r=0.426$ and $\mathbf{0 . 7 0 1}$ for concentration and excretion respectively. Mean serum concentrations of calcium, sodium chloride, phosphate, and alkaline phosphatase were normal and similar in the three groups.

Uric acid excretion and concentration for 67 inflammatory bowel disease patients are presented in Table III. Mean uric acid excretion in granulomatous bowel disease patients $(520 \mathrm{mg}$ per $24 \mathrm{hr}$ ) slightly exceeded uric acid excretion in either ulcerative colitis patients $(458 \mathrm{mg}$ per $24 \mathrm{hr}$ ) or the controls (451 mg per $24 \mathrm{hr}$ ). Whereas eight of 47 inflammatory bowel disease patients excreted more than $700 \mathrm{mg}$ in $24 \mathrm{hr}$, none of the control group reached this level of excretion. Mean urinary uric acid concentration was significantly increased among both groups of patients with inflammatory bowel disease. These concentrations among ulcerative colitis patients, granulomatous bowel disease patients, and control subjects were $538(\mathrm{P}<0.05), 558(\mathrm{P}<0.02)$, and $383 \mu \mathrm{g} / \mathrm{ml}$ respectively. Ten of 47 inflammatory bowel disease patients had concentrations exceeding $700 \mu \mathrm{g} / \mathrm{ml}$. This concentration was not reached by any of the control subjects. Mean 24-hr urine volumes on which uric acid was determined were similar at $1,068 \mathrm{ml}, 1,155 \mathrm{ml}$, and $1,210 \mathrm{ml}$ for ulcerative colitis patients, regional enteritis patients, and control subjects respectively. Though no patient was clinically dehydrated, concentration of uric acid varied inversely with urine volume ( $r=0.51$ for ulcerative colitis and 0.65 for regional enteritis).

Mean serum uric acid concentrations were $\Omega$ similar at $5.4 \mathrm{mg} / 100$ in patients with granulo- $\stackrel{?}{\rightleftharpoons}$ matous bowel disease, $4 \cdot 7$ in patients with $\underset{\vec{F}}{\vec{F}}$ ulcerative colitis, and 4.6 in the control group. $\frac{\text { ? }}{0}$ However, eight of 64 inflammatory bowel $\frac{1}{5}$ disease patients had serum uric acid values ex- $\frac{\bar{c}}{\bar{D}}$ ceeding $6.5 \mathrm{mg} / 100 \mathrm{ml}$, the highest concentration $\vec{\nabla}$ reached by any of the controls.

Mean morning urinary $p \mathrm{H}$ readings were कै $5.5,5.9$, and 5.8 for ulcerative colitis, granulo- $\overrightarrow{0}$ matous bowel disease, and control patients respectively. This greater urine acidity among $\omega_{\sigma}$ the ulcerative colitis patients was statisticallye significant $(\mathrm{P}<0.01)$.

\section{Discussion}

The pathogenesis of kidney stones in the majority of stone formers remains poorly understood. 을 Definition of the syndromes of cystinuria, $\vec{\varphi}$ oxaluria, and idiopathic hypercalciuria has emphasized the potential pathogenetic importance of increased excretion and concentration of various urinary crystalloids. On the other hand, altered physiochemical properties of the urine may favour stone formation in the presence of normal $\stackrel{2}{\circ}$ crystalloid concentration. The recent experi- $\varrho$ mental model of Vermeulen and Lyons (1968) $\overrightarrow{0}$ highlights the necessity for distinguishing be- $\exists$ tween concentration and total excretion of crystalloids in the pathogenesis of stone. Using the inert substance oxamide, these authors were able to distinguish 'triggering' and 'sustaining' factors in stone formation. Only animals with high initial ('triggering') concentrations of the crystalloid in the urine, followed by continued lower ('nourishing') concentrations developed $\mathrm{O}$ renal stones. Neither circumstance alone sufficed. These studies emphasize the potential importance of brief, raised concentrations of crystalloid as a necessary condition for stone nidation.

The present study demonstrates that many $N$ patients with inflammatory bowel disease excrete $\mathcal{W}^{-}$ more calcium and uric acid than do controlog subjects with functional bowel disease. Perhaps

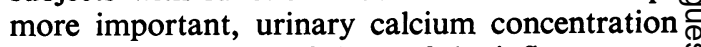
was elevated in one of three of the inflammatory $\stackrel{?}{+}$

\begin{tabular}{|c|c|c|c|c|}
\hline Disease & No. of Patients & $\begin{array}{l}\text { Uric Acid Excretion } \\
(\bar{x} \pm S E M, m g / 24 h r)\end{array}$ & $\begin{array}{l}\text { Uric Acid } \\
(\bar{x} \pm S E M\end{array}$ & $\begin{array}{l}\text { Concentration } \\
, \mu g(m l)\end{array}$ \\
\hline $\begin{array}{l}\text { Ulcerative colitis } \\
\text { Granulomatous bowel disease } \\
\text { Functional bowel disease }\end{array}$ & $\begin{array}{l}25 \\
22 \\
20\end{array}$ & $\begin{array}{l}458 \pm 46(4)^{1} \\
521 \pm 45(4) \\
451 \pm 32(0)\end{array}$ & $\begin{array}{l}538 \pm 67 \\
558 \pm 62 \\
383 \pm 30\end{array}$ & $\begin{array}{l}{[5]^{2,3}} \\
{[5]^{4}} \\
{[0]}\end{array}$ \\
\hline
\end{tabular}

Table III Urinary uric acid excretion and concentration

${ }^{1}()=$ no. patients $>700 \mathrm{mg} / 24 \mathrm{hr}$

'[] $=$ no. patients $>700 \mu \mathrm{g} / \mathrm{ml}$

${ }^{3} \mathbf{P}<0.05$

$P<0.02$ 
bowel disease patients (Table II), and mean urinary uric acid concentration (Table III) was significantly increased in both ulcerative colitis and granulomatous bowel disease patients.

The experimental design imposed certain limitations. Because the study coincided with ongoing clinical care of the patients, complete data were available on half the total study group. The dietary prescription was not fixed but did vary within strict limits; such conditions are the norm in other published studies of calcium and uric acid excretion. The values observed among the control groups in the present study were similar to other published data collected under similar dietary conditions (see below). Further, the diets of the study groups were possibly more restricted with respect to calcium and purines, within the limits noted, than those of the control patients, which should tend to minimize rather than exaggerate the observed differences in urinary crystalloid excretion. The administration of corticosteroids to the majority of inflammatory bowel disease patients and none of the controls is of major importance because of the known effects of steroids on calcium and uric acid excretion (Bartter, Fourman, Albright, Forbes, Jefferies, Griswold, Dempsey, Bryant, and Carroll, 1950; Ingbar, Kass, Burnett, Relman, Burrows, and Sisson, 1951). The changes in crystalloid excretion demonstrated in this study may therefore represent consequences of such treatment, in addition to factors inherent in the intestinal disorders. No similar large group of such inflammatory bowel disease patients not treated with steroids may be found, however, to document the relative contribution of this factor to the observed differences in crystalloid excretion.

Peacock, Hodgkinson, and Nordin (1967) have re-emphasized the importance of dietary calcium in the definition of hypercalcuria. On calcium intakes of 400 to $800 \mathrm{mg}$ per day, as in the present study, excretion of $250 \mathrm{mg} / 24 \mathrm{hr}$ is considered the upper limit of normal (Epstein, 1968; Melick and Henneman, 1958). Patients with hyperparathyroidism and idiopathic hypercalciuria who formed stones exhibited mean urinary calcium excretions of $196 \mathrm{mg}$ and $235 \mathrm{mg} / 24 \mathrm{hr}$ respectively (Melick and Henneman, 1958). The mean calcium excretion in the present ulcerative colitis group $(212 \mathrm{mg} / 24 \mathrm{hr})$ is well within this range. In addition, 11 of 34 patients with inflammatory bowel disease excreted more than $250 \mathrm{mg}$ per day, a level reached by none of the controls. Perhaps more important, calcium concentration exceeded $20 \mathrm{mg} / 100 \mathrm{ml}$ in eight of 37 inflammatory bowel disease patients compared with such a concentration in only one of 10 control subjects.

Increasing urinary sodium excretion may positively influence calcium excretion (Chakmakjian and Bethune, 1966), and the positive correlation between sodium and calcium excretion in both groups of inflammatory bowel disease subjects suggests a potential relationship between excretion of these anions. However, mean calcium excretion was most elevated in ulcerative colitis whereas mean sodium excretion was most elevated in regional enteritis suggesting that multiple factors may influence calcium excretion in these patients.

Uricosuria in excess of $700 \mathrm{mg}$ per day on a moderately restricted protein intake is considered excessive (Gutmann and Yü, 1968). Gutman and Yü (1968) noted an increased incidence of uric acid stones in those patients with primary gout or hyperuricaemia of undetermined origin who excreted more than $700 \mathrm{mg}$ of uric acid in the urine per day (Gutman and Yü, 1968; Yü and Gutman, 1967). In our study, eight of 47 inflammatory bowel disease patients, but none of the controls, excreted more than $700 \mathrm{mg}$ of uric acid per day. The significantly higher mean uric acid concentration in both groups of inflammatory bowel disease patients compared with the controls is perhaps more important. In addition, 10 of 47 inflammatory bowel disease patients, but none of the controls, had urinary uric acid concentrations exceeding $700 \mu \mathrm{g} / \mathrm{ml}$. Though mean 24-hr urine volumes during the uric acid study were nearly identical for three groups, the negative correlation between urine volume and uric acid for ulcerative colitis and regional enteritis patients suggests that the state of hydration may play a role in the higher uric acid concentrations observed. However, mean 24-hr urine volumes were over $1,000 \mathrm{ml}$ for both groups, suggesting that other factors may also contribute to the pathogenesis of the differences.

The results of this investigation, though preliminary, indicate increased excretion and higher urinary concentration of calcium and uric acid in some patients with inflammatory bowel disease on the usual treatment programmes. Since none of these patients developed kidney stones during the course of the investigation, they need not represent crystalloid excretion patterns in inflammatory bowel disease patients who do form stones. However, the level of increased excretion of these crystalloids is consistent with data from other groups of stoneforming patients in whom similar excretion patterns have been incriminated in stone pathogenesis. In addition, the present demonstration of higher concentrations of urinary calcium and uric acid is consistent with the recent emphasis on transient high concentrations of urinary crystalloid as an important factor in kidney stone formation. Only very long-term prospective studies of such patients will definitely document the true contribution of these increased crystalloid concentrations and excretions to kidney stone formation in inflammatory bowel disease patients.

The authors wish to thank Dr Leif Sorenson, Department of Medicine, University of Chicago, for performing the enzymatic serum and urine uric acid determinations in his laboratory. 
References

Bartter, F. C., Fourman, P., Albright, F., Forbes, A. P., Jefferies, W. M., Griswold, G., Dempsey, E., Bryant, D., and Carroll, E. (1950). The effect of adrenocorticotropic hormone in panhypopituitarism. J. clin. Invest., 29, 950-971.

Boyce, W. H., Garvey, F. K., and Strawcutter, H. E. (1956). Incidence of urinary calculi among patients in general hospitals 1948-1952. J. Amer. med. Assoc., 161, 1437-1442.

Chakmakjian, Z. H., and Bethune, J. E. (1966). Sodium sulfate treatment of hypercalcemia. New Engl. J. Med., 275, 862-869.

Deren, J. J., Porush, J. G., Levitt, M. F., and Khilnani, M. T. (1962). Nephrolithiosis as a complication of ulcerative colitis and regional enteritis. Ann. intern. Med., 56, 843853.

Epstein, F. H. (1968). Calcium and the kidney. Amer. J. Med., $45,700-714$.

Gelzayd, E. A., Breuer, R. I., and Kirsner, J. B. (1968). Nephrolithiasis in inflammatory bowel disease. Amer.J.dig. Dis., 13, 1027-1034.

Gutman, A. B., and Yü, T. F. (1968). Uric acid nephrolithiasis. Amer.J. Med., 45, 756-779.

Ingbar, S. H., Kass, E. H., Burnett, C. H., Relman, A. S., Burrows, B. A., and Sisson, J. H. (1951). The effects of ACTH and cortisone on the renal tubular transport of uric acid, phosphorus, and electrolytes in patients with normal renal and adrenal function. J. Lab. clin. Med., 38, 533-541.
Mařatka, Z., and Nedbal, J. (1964). Urolithiasis as a complication of the surgical treatment of ulcerative colitis. Gut, 5 , 214-217.

Melick, R. A., and Henneman, P. H. (1958) Clinical and laboratory studies of 207 consecutive patients in a kidneystone clinic. New Engl.J. Med., 259, 307-314.

Peacock, M., Hodgkinson, A., and Nordin, B. E. C. (1967). Importance of dietary calcium in the definition of hypercalciuria. Brit. med. J., 3, 469-471.

Smith, L. H. Jr. (1968) Symposium on stones. Introduction. Amer.J. Med., 45, 649-653.

Sorensen, L. B. (1960). The elimination of uric acid in man studied by means of $\mathbf{C}^{14}$-labelled uric acid uricolysis. Scand. J. clin. Lab. Invest., 12, Suppl. 54.

Vermeulen, C. W., and Lyon, E. S. (1968). Mechanisms of genesis is and growth of calculi. Amer. J. Med., 45, 684-692.

Yü, T. F., and Gutman, A. B. (1967). Uric acid nephrolithiasis $\vec{\square}$ in gout. Predisposing factors. Ann. intern. Med., 67, 1133-1148. 